\title{
The Role of Corporate Management in an Effective Crisis Management Program
}

\author{
Robert S. Fleming \\ Rohrer College of Business \\ Rowan University, New Jersey, USA \\ Faye X. Zhu \\ Rohrer College of Business \\ Rowan University, New Jersey, USA
}

\begin{abstract}
Contemporary businesses face many challenges that have the potential of compromising their success and, at times, survival. These challenges include "weathering the storm" when an organization is confronted with a crisis event or situation. A crisis may originate within an organization, as in the case of a defective product, financial or legal impropriety, or a security breach compromising customer information; or from an external source, as in the case of a catastrophic weather event or labor strike impacting an organization's operations. The importance of a proactive approach in advance of, during, and following a crisis event has demonstrated its merit in enhancing an organization's ability to prepare for, live through, and recover from a crisis event. This paper considers the importance of a proactive crisis management program in contributing to organizational resilience to "weather the storm" of a crisis event successfully and the essential role that corporate managers play in an effective crisis management program.
\end{abstract}

Keywords: Crisis management, Corporate management, Crisis communication, Business continuity, Organizational resilience, Reputation management

\section{INTRODUCTION}

While there are many challenges that a contemporary organization may face, one of growing practical and research interest has been the potential of facing a crisis event or situation. Crisis situations are inherent in the activity of any contemporary organization regardless of type (Mitut, 2011). Crisis situations impacting an organization may originate from both external and internal sources. Every organization faces the risk of crisis as the environment in which it operates continues to change constantly and present threats to its business operations and survival (Glamuzina and Lovrincevic, 2013).

Crisis management is a systematic attempt to prevent organizational crises and to manage those that do occur. Organizations have an essential role in studying internal and external factors responsible for crisis situations and identifying strategies for preventing crises and effectively and efficiently managing those that do occur. The capability to manage unexpected crisis situations strategically is a major strength of a contemporary organization (Taneja et al., 2014). The ability to manage a crisis has been identified as an important management skill set (Coombs, 2007). Crisis leadership skills have increased in importance with the increase in global disasters in recent years (Thach, 2012).

The purpose of this paper is to review and examine current literature on the management of crises in organizations. It reports on the insights gleaned from a comprehensive literature review, as well as review of how certain organizations have responded to crisis situations. 
After considering the nature of and potential business impact of crisis events, the paper will discuss the expectations of various stakeholder groups during a crisis and the challenges that these expectations present to an organization experiencing a crisis event.

Review of the literature and situations where organizations experienced a crisis event reveals the importance of a proactive approach in preparing for, managing through, and recovering from a crisis. The study considered the importance of a proactive crisis management program designed ideally to prevent, and to respond successfully to and recover from those crises that do present themselves. A proactive crisis management approach will be advanced as an essential strategy in building the necessary organizational resilience to "weather the storm" of a crisis event or situation. A proactive approach is essential in enhancing a contemporary organization's resilience within the challenging, dynamic world of business.

A crisis management model will be introduced along with the importance of crisis management actions before, during, and after a crisis. The crucial role that corporate management plays during each phase of crisis management will be discussed. The important role of effective communication throughout a crisis will be emphasized, as will the importance of corporate leadership in preparing for, living through, and recovering from crises.

\section{Nature of Crisis Events}

\section{BACKGROUND}

While various authors, researchers, and practitioners define a "crisis" in different terms, there are certain common elements of these definitions that serve as a basis for the present study. These include the fact that a crisis situation or event demands time-sensitive attention, decision-making, and action in the interest of containing its potential impact on the organization. Crisis events are viewed as inevitable; it is not a question of if, but when a crisis will occur. Organizations have always been and will always be vulnerable to some form of crisis. The key elements that differentiate a crisis from normal business problems or challenges are ambiguity, high stakes, and perception of urgency (James and Wooten, 2005). In the current dynamic market environment, organizations are vulnerable to many problems which can result in a real business crisis (Mazanek, 2015).

Several representative definitions of a "crisis" provide a context for this study. Coombs (2007) defines a crisis as "a sudden and unplanned event that threatens to disrupt an organization's operations and poses both a financial and reputation threat." James and Wooten (2005) view a crisis as "a rare, significant, and public situation, which creates highly undesirable consequences for the enterprise and its stakeholders and requires from business leaders immediate corrective action." Others have defined a crisis as "a series of unforeseen events that can thrust an organization into a downward spiral that is quick and has potential long-term effects if the situation is not handled promptly, effectively, and efficiently" (Taneja et al., 2014) and "an unplanned (but not necessarily unexpected) event that calls for real-time, high-level strategic decisions in circumstances where making the wrong decisions, or not responding quickly or proactively enough, could seriously harm the organization" (Davies, 2005).

While the concept of relating a proactive approach to effective crisis management to organizational resilience is a fairly new topic of growing practical and research interest, how prepared an organization is to respond to crisis situations is certainly a determinant of its continued success and, in some cases, survival. Crisis events or situations can originate from external and/or internal sources. Often cited examples of external factors that result in crises impacting an organization, industry, or nation include economic and market forces. Natural disasters and severe weather events are, likewise, external factors that can present themselves 
as a crisis requiring appropriate and timely action on the part of an organization. Recent instances where the infrastructure on which an organization relies was compromised through service interruptions of essential mission-critical services provided by traditional utilities and internet service providers further illustrate external sources that can cast an organization into a crisis situation.

Crisis events resulting from internal sources are typically based on the actions or lack of actions that triggered them. The discovery of financial improprieties or illegal activities serve as prime examples of actions that can tarnish an organization's reputation, as well as often compromising its ability to survive the crisis and continue to succeed and prosper. Contemporary organizations may face similar challenges resulting from inappropriate or flawed business relationships. How an organization prevents and responds to defective products or product tampering, as well as catastrophic accidents, is a crucial aspect of ensuring organizational resilience to potential crisis events. Classic examples of such situations would include how Johnson \& Johnson handled the Tylenol product tampering a number of years ago, and the highly publicized handling by Exxon and British Petroleum (BP) of their respective oil spills.

An all too frequent crisis event in this age of information technology and the mission-critical role of this technology in the operations of many contemporary organizations involves technology failures. While the cause, scope, and impact of technology failures can vary, these crisis events can result in loss of data, security breaches, identity theft, service interruptions, and service failures. The fact that these events can not only compromise the effectiveness and efficiency of an organization's operations, but also can directly impact its customers and other stakeholders in the case of failure to protect their personal data and prevent identity theft, serve as a key factor in decisions of those with whom an organization does business deciding to take their business elsewhere.

\section{Business Impact of Crisis Events}

The potential business impact of a crisis event should be fully understood and never underestimated. Crises can impede the operations of an organization (Fragouli and Ibidapo, 2015), as well as damage an organization's reputation (Coombs and Holladay, 2014). Furthermore, a crisis can result in loss of operational control, concerned employees and owners, demoralized managers, and limited financial resources (Glamuzina and Lovrincevic, 2013).

The business impact will most certainly be determined by the nature and scope of a crisis. How an organization has positioned itself through advanced planning and action will influence the degree and impact of exposure. A number of organizational factors determine the degree of exposure that an organization faces during a crisis. Organizations with decentralized operations are often less vulnerable, particularly in the case of events that result in some facilities still being fully capable of continuing to perform their normal business activities, in comparison to those organizations that have centralized operations occurring at a single location or within a limited geographical region directly affected by a crisis. The operations impacted by a crisis situation will also determine the degree of exposure, as in the case of organizational units that perform mission-critical activities, including those with task interdependencies to other parts of an organization's operations.

The impact of exposure to a crisis event will be based on the extent to which it limits or suspends an organization's ability to conduct its business operations. Likewise, the length of 
the interruption must be considered, as illustrated by an organization that is unable to operate for several days until utilities are restored after a major weather event, in contrast to an organization whose facilities were significantly damaged or destroyed by a weather event or building fire. Another consideration is the additional costs of operating during the crisis.

The business impact of a crisis event often involves reduced sales or revenues. Should this be a prolonged situation, decreased market share and profits can also result. A crucial challenge in times of crisis is the retention of an organization's existing customers, as the loss of customers and/or contracts can trigger a downward spiral in business performance. An essential aspect of the business impact of a crisis is its potential to tarnish an organization's reputation. While this is an obvious reality when stakeholders learn about financial, regulatory, or legal improprieties, how proactive an organization is in preventing crisis situations and addressing those that do occur is an integral determinant of reputation management. The responsiveness of an organization in terms of both keeping its stakeholders informed throughout a crisis and addressing the situation in an effective and efficient manner so as to resume normal business operations is essential. Obviously, the worst possible business impact is for an organization to experience business failure.

\section{Enhancing Organizational Resilience Through A Proactive Approach}

Successful organizations recognize the importance of assuming a proactive management approach that positions their organization to achieve desired business success as they strive to achieve their organizational mission. While a proactive approach can contribute to many aspects of organizational success, the merit of proactive management has not always been recognized in preparing organizations to prevent potential crisis situations and address those crisis events that do occur. The traditional event approach viewed crisis management as a largely tactical activity focused on incident response in terms of preparing for crisis events and responding to those that do occur. The trend in recent years has involved advanced preparation as opposed to traditional reactive crisis response. A new approach to crisis management is emerging that moves beyond a reactive approach to one that seeks to discover new opportunities for organizations (Jacques, 2010).

The importance of proactive crisis management cannot be overemphasized. How an organization handles a crisis is more important than how things were before the crisis (Heller and Darling, 2012). Every organization should have a plan in place for preventing and managing crisis events. The advantage of having a pre-existing crisis management plan is that, in addition to contributing to the effective and efficient handling of the crisis when it arises, it also provides the ability to detect crisis potential before one actually occurs and delineates mitigation actions that can be taken. "During a crisis, everything counts. If systems had not been put in place in advance, then a hurriedly put together crisis communication strategy may cause the organization to further crumble," (Lando, 2014). This statement illuminates the crucial importance of a proactive approach that ensures that the organization is prepared to skillfully enact and orchestrate its crisis management plan should a crisis strike.

An essential element of a crisis management plan is the crisis communication plan. How an organization communicates during a crisis can make it or break it. Organizations must be proactive and develop a crisis communication plan (Telang and Deshpande, 2016). A crisis communication plan should delineate how the organization intends to communicate with its various stakeholder groups before, during, and after the occurrence of a crisis. The value of crisis communication during these three phases of crisis management cannot be ignored (Fearn-Banks, 2007). An organization's crisis communication plan should include appropriate crisis communication strategies necessary to achieve damage control, while at times turning 
the crisis into a growth opportunity for the organization (Telang and Deshpande, 2016).

It is imperative that those responsible for crisis management on behalf of a contemporary organization recognize the impact that the Internet and social media have had on crisis communication. The fact that anyone can become a "reporter" and disseminate information to an almost endless audience complicates organizational crisis communication activities. A growing number of organizations, recognizing the potential for the dissemination of inaccurate, confusing, or misleading information by other parties, assign a communications professional to monitor the Internet and social media in the interest of uncovering the need to ensure that information received by organizational stakeholders and others is accurate and credible.

\section{Stakeholder Expectations During A Crisis}

The obvious focus of any organization that has faced a crisis is to "get back to normal." What that means will depend on the nature, scope, and impact of a crisis event. In the case of an organization whose operations were halted as a result of the crisis, as in the case of a major weather event forcing a facility closure(s), the interest is to get "back in business." As important as this interest of an organization and its management is, it is imperative that the needs and expectations of the organization's various stakeholders are fully understood, appreciated, and addressed in a timely manner.

While an organization will have many stakeholder groups, each with its own expectations and sometimes conflicting demands on an organization, the three stakeholder groups that are typically considered the most important when conducting a stakeholder impact analysis are customers, employees, and owners. In the above example, employees want to get back to work in the interest of maintaining their income stream, customers seek the restoration of the organization's ability to deliver desired products and/or services, and owners look forward to the continued financial performance of the organization. Other stakeholder groups potentially impacted by the above crisis could be the organization's suppliers who are interested in continuing to provide goods and services to the organization, and its creditors who desire to be paid according to established terms.

While the importance of identifying and understanding the expectations of all of these stakeholder groups remains, it is important to realize that the relative importance of each group could possibly vary based on the nature of a crisis event. The findings of one study suggest that while customers and employees were found to be among the most important stakeholder groups, creditors in certain instances may rise in their importance as a stakeholder group, while owners might actually decrease in relative importance (Glamuzina and Lovrincevic, 2013).

Communication is a key component in determining organizational success in dealing with a crisis (Mazanek, 2015). A common interest of the various organizational stakeholder groups is that they receive accurate, complete, credible, professional, and timely information from the involved organization throughout the crisis. Coombs (2007) describes crisis communication as "a relatively young discipline born of the need to address very real problems" as well as the value of monitoring stakeholder reactions on social media as "barometers of the effectiveness of an organization's crisis response." His research also indicated that stakeholders can function as informal crisis managers and that their communication, if inaccurate, confusing, or misleading, can actually undermine the organization's crisis management initiatives. 
Corporate management plays a critical role in ensuring that realistic and reasonable stakeholder expectations are fully met and, ideally, at times exceeded. This leadership can be the difference between organizational success and survival, having a strong motivating and organizational effect (Mitut, 2011). Organizational leaders are responsible for successful crisis management and how affected stakeholders are managed and should engage impacted stakeholders in developing crisis management strategies. Organizational culture also plays a role in the successful development and implementation of a crisis management plan. Executives in a culture of complacency and chronic crisis tend to focus on tactical rather than strategic issues. Complacency can facilitate and deepen crises as the presence of complacency serves to blind executives to emerging crises and curtails their ability to counter them (Ali, 2014).

\section{THE CRISIS MANAGEMENT PROCESS}

The various crisis management models that have been advanced have several commonalities in that they all portray crisis management as a process involving a number of stages coinciding with the respective phases of a crisis. Two respected models have been selected to provide a context for first considering necessary activities throughout a crisis event and subsequently the role of corporate managers throughout the management of a crisis.

Coombs (2012) developed a three-stage crisis management model that includes pre-crisis, crisis, and post-crisis stages. While the pre-crisis stage includes actions that are performed before encountering a crisis, the model acknowledges that since not all crises can be prevented, organizational members must be prepared to handle those that do occur. The pre-crisis stage consists of three sub-stages: signal detection, prevention, and crisis preparation. Once a potential crisis has been detected, actions must be initiated to prevent its occurrence. The crisis stage begins with a triggering event and consists of two sub-stages: crisis recognition and crisis containment. Communication with stakeholders is crucial during this stage. Crisis containment focuses on the organization's crisis response. The post-crisis stage involves actions that are intended to ensure that the crisis is actually over, to better prepare an organization for the next crisis it may face, and to ensure that stakeholders are left with positive perceptions of the organization's crisis management efforts.

Heller and Darling (2012) advance a four-stage crisis management model. The model acknowledges that a crisis can have long or short duration, can consist of as many as four different and distinct phases, and that in some cases these phases can be so closely related that they combine. During the preliminary (pre-crisis) stage, an organization may be provided limited advanced warning of a pending crisis situation. The acute crisis stage is characterized by at least some damage having occurred as a result of the crisis, with the potential for additional damage being somewhat influenced by the quality and integrity of corporate leadership. A prolonged crisis would transition into the chronic crisis stage. During the final stage of crisis reduction, the organization's goal of resolving the crisis is achieved, as is the desire to turn the crisis situation into an opportunity, if possible.

These crisis management models and others provide a context for the present study. The lessons learned regarding the roles of corporate managers in crisis management will first be considered in general terms. The specific roles of corporate managers will then be discussed with respect to four acknowledged stages or phases of crisis management. The first two involve actions of corporate management before the occurrence of a crisis and involve preventing crisis events and preparing for those crises that may occur. The third will consider appropriate actions of corporate management during a crisis event. The final phase will consider the post-crisis role that corporate management can play as their organization strives 
to recover and learn from a crisis event.

\section{ROLES OF CORPORATE MANAGERS IN CRISIS MANAGEMENT}

In considering the roles that corporate managers should play during a crisis, it is important to acknowledge that there is a profound difference between corporate management and corporate leadership. Heller and Darling (2012) clearly articulate this difference in stating, "Corporate managers are people who do things right, and corporate leaders are people who do the right things." They further advocate that how corporate managers understand and enact their responsibilities during a crisis determines whether they are also corporate leaders and if effective crisis management becomes a reality through the development of meaningful corporate leadership strategies.

James and Wooten (2005) identify six core competencies in crisis leadership: building trust, willingness to share information, creating a new corporate mindset, identifying vulnerable areas, taking courageous action, and learning from the experience for effective change. They also advocated that the best crisis leaders build a foundation of trust that prepares their organization for difficult times and that the leadership demonstrated during a crisis is a major determinant of organizational success after a crisis. The importance of inspiration in terms of giving followers hope and setting the right level of motivation is also imperative, given that motivated personnel will perform well beyond expectations (Sailor, 2013).

Successful crisis management requires the strong leadership of corporate managers. Crises require leaders who do not follow the norm and are able to formulate strategies to manage the crisis and to bring about change and growth in their organization. In times of crisis, organizational leaders need to be visible within and beyond their organization, as this offers some stability to the situation and the organization (Fragouli and Ibidapo, 2015). Leadership also contributes to maintaining a positive organizational climate (Mazanek, 2015).

Strategies implemented during a crisis can result in two diametrically opposed outcomes organizational survival or failure (Fragouli and Ibidapo, 2015). Successful crisis solutions don't occur spontaneously; they are triggered by the creativity and courage of corporate management (Glamuzina and Lovrincevic, 2013). The important role that corporate managers play also includes the essential action of incorporating crisis management into the organization's systems (Taneja e al., 2014). One of the most dangerous aspects of dealing with a crisis is to view it only from an economic cost standpoint: a mistake that augments the problem and can lead to further economic setbacks (Ali, 2014). The conceptual perspective and orientation of corporate managers position them to comprehend and address all relevant aspects and impacts of a crisis situation fully.

An integral role of corporate managers during a crisis involves reputation management. In a sense this role is often accomplished based on the successful actions of corporate managers before, during, and after a crisis. Virtually nothing can damage an organization's reputation more rapidly and severely than the impact of a major crisis (Jacques, 2010). Image management is important during a crisis, given that crisis situations usually result in negative publicity which threatens an organization's image and reputation (Weber et al., 2011).

The significant role that corporate managers play as corporate leaders in times of crisis should be clear, as should be the crucial roles that these organizational leaders must enact during a crisis event impacting their organization. The dedication, commitment, and passion that these organizational leaders demonstrate through their involvement, actions, and leadership before, 
during, and following a crisis clearly serve to demonstrate the organization's commitment to "weather the storm" of crises in the interest of ensuring the organization's ability to survive any and all challenges associated with the crisis so as to continue to succeed in fulfilling its mission and meeting and, ideally, exceeding the expectations of its stakeholders.

The following sections of this paper will consider specific actions that corporate managers can take during the various phases of crisis management. These build on and complement the general actions discussed in this section.

\section{Preventing Crisis Events}

While organizations most certainly must be prepared to effectively and efficiently address crises that occur, the ideal is to avoid these undesirable situations or at least to minimize their impact on the organization through proactive action before their occurrence. Crisis preparation has thus evolved as an issue of increasing importance as organizational leaders seek to prevent, or effectively address, impending crises (Taneja et al., 2014).

Corporate managers have an important role to play in preventing crises that have the potential of harming their organization. They should engage in continual environmental scanning to reveal signs of a crisis (James and Wooten, 2005). Adopting a proactive crisis management strategy that incorporates crisis prevention, rather than just crisis response, necessitates moving responsibility from the operational to the executive level (Jacques, 2010).

Corporate managers clearly demonstrate corporate leadership and stewardship through their commitment to crisis prevention. Likewise, their active involvement in crisis prevention efforts demonstrate to the organization's employees, customers, and other stakeholder groups that the organization is committed to preventing crisis events that could impact its ability to continue to succeed in fully meeting and, ideally, exceeding their expectations.

\section{Preparing for a Crisis}

Successful crisis management involves actions that an organization takes before, during and after a crisis. Corporate managers have an integral role as an organization prepares for potential crises, operates during those crises that do occur, and recovers from them. The success of an organization's crisis management efforts in the two stages that follow are, in large part, determined by its crisis preparation commitment and activities. Organizations that utilize early detection methods and have existing crisis management plans before they face a crisis are better prepared to manage and survive a crisis event and have the opportunity to reposition themselves and turn a crisis into a strategic opportunity (Applebaum, Keller, Alvarez, and Bedard, 2012).

Corporate managers have an essential role in ensuring that their organizations not only have a realistic crisis management plan, but that their employees have received the necessary training to fully understand and enact their respective roles and responsibilities under the crisis management plan. The existence of a crisis management plan demonstrates an organization's commitment and preparedness to handle crises.

While many organizations have a crisis management plan, many organizations are ill-prepared in that their plan does not address crisis communication issues and strategies (Lando, 2014). The consequence of not having a robust crisis communication plan that outlines communication roles during a crisis can be the dissemination of inaccurate, confusing, or misleading information by others, including the news media and social media. 


\section{Operating during a Crisis}

Corporate managers have instrumental roles during a crisis in two important respects. They are responsible for ensuring that organizational members within their area of responsibility are effectively and efficiently enacting their roles and responsibilities as defined in the organization's crisis management plan. This routinely involves motivating and empowering their employees and emphasizing the importance of their actions to a successful crisis outcome. It also involves ensuring that employees have the necessary resources to operate successfully during the crisis event.

Corporate managers will often have an active role in crisis communication activities through developing or approving media releases, participating in press conferences, and making themselves available for media interviews. The media provides an opportunity to deliver accurate information to the public and maintain or regain public trust and/or support.

During a crisis it is essential to define and orchestrate diverse communication roles and activities tailored to an organization's communication goals and that communicators be creative, inspiring, and adaptive, establishing a professional and productive relationship with the media (Lando, 2014). Crisis communication is very important during a crisis situation and should therefore be clear, free from ambiguity, and directed towards creating a positive image of the organization following a crisis (Telang and Deshpande, 2016).

Throughout a crisis it is essential that the organization provide its employees and other stakeholders with accurate, complete, credible, professional and timely information about the situation. While complete information may not be immediately available, an organization's desire and willingness to share what it knows in a timely manner goes a long way in enhancing its image and reputation in the eyes of its stakeholders. While many organizations will utilize seasoned communication professionals as public information officers, the presence and involvement of corporate management in press conferences, interviews, and media releases sends an important message regarding their organization.

\section{Recovering from a Crisis}

Corporate managers play a vital role in an organization's recovery after a crisis. They should insist on a complete review of the crisis and conduct an after-action critique at the executive level of the organization. The goal should be to discover the causal factors that lead to the crisis, how their organization responded to the crisis, and to learn what the organization can do in the future to be better prepared to prevent or "weather the storm" of future crisis events. This review should focus on the adequacy of the organization's crisis management plan, policies and procedures; whether the plan, policies and procedures were properly implemented; and the success of the organization in countering the crisis.

A complete review of relevant information disseminated by the organization and other parties during the crisis event should be conducted in the interest of identifying inaccurate, confusing, or misleading information in need of correction, as well as the sources of such information. This review must include the use of the Internet and social media platforms during the crisis by the organization and other parties that disseminated information about the organization or the situation it was facing. The lessons learned from this critique can be invaluable in reviewing and revising, as necessary, the organization's crisis management plan, policies, and procedures.

As mentioned earlier, it is always important to ascertain that the crisis and its impacts have actually ended. In so doing it is essential to look for ripple effects that may occur after the 
crisis. Should these be revealed, it is crucial that they be appropriately addressed in a timely manner.

An important and often overlooked activity during crisis recovery is to acknowledge the dedicated efforts of the organization's employees who, through taking ownership for their defined roles and responsibilities under the organization's crisis management plan, enabled their organization to mitigate the crisis successfully. Without their support and assistance an organization's crisis management initiatives would often be ineffective.

Last, but certainly not least, corporate managers must utilize their conceptual skills and strategic mindset to look for ways of transforming a crisis event into an opportunity for their organization. It is likewise important to learn from a crisis and incorporate this understanding into future crisis management activities.

\section{CONCLUSIONS}

The research interest of this study was to determine the importance of a proactive crisis management program in preparing an organization to "weather the storm" of a crisis successfully and to consider the role of corporate managers in an organization's crisis management activities. The importance of both a proactive approach and the involvement of corporate managers in an organization's crisis management activities were confirmed through review of the literature and practical situations involving contemporary organizations.

Corporate managers play an instrumental role in the success of any contemporary organization. Both their organizational position and managerial skill set equip them to be entrusted with the mission-critical issue of crisis management. In addition to the various roles that they routinely enact during the "good times," these organizational leaders play an integral role in preparing their organization to avoid most crises and to address and recover successfully from those it does encounter. Their commitment to and support of its crisis management activities are instrumental in preparing their organization to address the many anticipated and unexpected crisis situations inherent to the contemporary business world.

The researchers intend to further expand this exploratory study in the interest of enhancing the understanding of the relationship that exists between proactive crisis management and organizational resilience. A focal point of future research will be the role of corporate managers in these mission-critical organizational initiatives.

\section{References}

Ali, A. (2014). Complacency and crisis management in large organizations. International Journal of Commerce and Management, 24(4), 278-284.

Appelbaum, S., Keller, S., Alvarez, H., and Bedard, C. (2012). Organizational crisis: Lessons from Lehman Brothers and Paulson \& Company. International Journal of Commerce and Management, 22 (4), 286-305.

Coombs, T. (2007). Protecting organizational reputations during a crisis: The development and application of situational communication theory. Corporate Reputation Review, 10(3), 163-176.

Coombs, T. (2012). Ongoing Crisis Communication: Planning, Managing, and Responding. Thousand Oaks, CA: Sage.

Coombs, T., and Holladay, S. (2014). How publics react to crisis communication efforts: Comparing crisis response reactions across sub-arenas. Journal of Communication Management, 18(1), 40-57.

Davies, D. (2005). Crisis management: Combating the denial syndrome. Computer Law and Security Report, 21(1), 68-73.

Fearn-Banks, K. (2007). Crisis Communications: A Casebook Approach. London: Lawrence Erlbaum Associates.

Fragouli, E., and Ibidapo, B. (2015). Leading in crisis: Leading organizational change \& business development. 
Journal of Information, Business and Management, 7(3), 71-90.

Glamuzina, M., and Lovrincevic, M. (2013). Corporate crisis and crisis strategy implementation. Montenegrin Journal of Economics, 9(2), 89-100.

Heller, V., and Darling, J. (2012). Anatomy of crisis management: Lessons from the infamous Toyota case. European Business Review, 24(2), 151-168.

James, E., and Wooten, L. (2005). Leadership as (un)usual: How to display competence in times of crisis. Organizational Dynamics, 34(2), 141-152.

Jaques, T. (2010). Reshaping crisis management: The challenge for organizational design. Organization Development Journal, 28(1), 9-17.

Lando, A. (2014). The critical role of crisis communication plans in corporations' crises preparedness and management. Global Media Journal, Canadian edition, 7(1), 5-19.

Mazanek, L. (2015). Leadership during crisis: Threat identification and solution proposal. Trendy Ekonomiky a Managementu, 9(24), 61-70.

Mitut, I. (2011). The role of leadership in the management of crisis situations. Romanian Economic and Business Review, 6(3), 20-33.

Sailor, E. (2013). Leadership during times of crisis. Journal of California Law Enforcement, 47(4), 11-16.

Taneja, S., Pryor, M., Sewell, S., and Recuero, A. (2014). Strategic crisis management: A basis for renewal and crisis prevention. Journal or Management Policy and Practice, 15(1), 78-85.

Telang, A., and Deshpande, A. (2016). Keep calm and carry on: A crisis communication study of Cadbury and McDonalds. Management and Marketing, 11(1), 371-379.

Thach, L. (2012). Managerial perceptions of crisis leadership in public and private organizations: An interview study in the United States. International Journal of Management, 29(2), 712-725.

Weber, M., Erickson, S., and Stone, M. (2011). Corporate reputation management: Citibank's use of image restoration strategies during the U.S. banking crisis. Journal of Organizational Culture, Communications, and Conflict, 15(2), 35-55. 